\title{
MAPPING THE TRANSPORT INNOVATION PERFORMANCE OF REGIONS IN EUROPE
}

\author{
Rob Konings ${ }^{1}$, Erik Louw ${ }^{2}$ \\ ${ }^{1,2}$ Delft University of Technology, Faculty of Architecture, OTB Research Institute for the Built \\ Environment, Julianalaan 134, 2628 BL Delft, The Netherlands
}

Received 25 February 2016; accepted 25 May 2016

\begin{abstract}
The innovation policy of the European Union is based on the concept of smart specialization of regions, which means that regions should focus on their comparative strengths. With respect to this policy on transport innovations there is an interest to gain insights in the comparative innovation performances and capacities of regions in the transport sector. Innovation performances and capacities are, however, complex concepts.

This paper elaborates an approach to measure and explain the innovation performance of the transport sector at regional level. The approach is based on structural equation modelling and applied to 251 European regions.

The results show that high performing regions are predominantly found in Germany and Sweden, while low performing regions are located in Finland, Poland, Romania, Bulgaria, Hungary, Spain and United Kingdom. However, the scores of regions on innovation performance are rather different when the performance is measured for the transport manufacturing and transport service sector individually. Among the factors that may explain transport innovation performance of regions funding possibilities appear to be important, while the relevance of innovation milieu is limited.
\end{abstract}

Keywords: transport innovation, innovation indicators, regional analysis, structural equation modelling, Europe.

\section{Introduction}

Transport is a key enabler of economic and social activity and a major sector in the European economy. The transport sector employs about 12 million people, of which more than 10 million are working in the service sector and the remainder in the manufacturing sector. The total sector represents $6 \%$ of the total European employment and generates $7 \%$ of gross domestic product (GDP) in the EU (European Union, 2013).

The European transport system is one of the world's best qualified systems, but nevertheless faces major challenges. Growth in passenger and freight transport demand has increased significantly in the last decades and is predicted to rise further. However, overall infrastructure capacity is reaching its limits and (financial) possibilities to expand transport infrastructure significantly are also limited. The challenge is to make more efficient use of existing infrastructure, while meeting higher requirements for safety, security and reliability as well as user convenience (European Union, 2012).

The unabated growth in transport demand also endangers the target of achieving a $60 \%$ reduction in greenhouse gas emissions by

\footnotetext{
${ }^{1}$ Corresponding author: j.w.konings@tudelft.nl
} 
2050 from the 1990 level. The increase in total emissions that result from transport growth will likely offset possible reductions of new efficient technologies. Development of more energy-efficient technologies and stimulation of the use of more sustainable transport solutions are therefore needed.

Last but not least, the leadership position of the European transport manufacturing (vehicles and other transport equipment) is challenged. The emerging role of in particular Asian countries endangers the European competitiveness and hence employment.

Innovation is considered essential for the European transport strategy to tackle these challenges. Innovations should lead to more efficient, environmentally sound and more intelligent transport in Europe and to more competitiveness of the European transport industry in developing and selling such new, smart transport solutions.

The conditions for realizing innovations and being successful in implementation will vary in Europe, not only at country level but also at regional level. It is useful to identify these regional differences to support the EU innovation policy that is based on smart specialization of regions, which means that regions should focus on their comparative strengths. According to this policy regions can get support of EU for their strongest and promising domains for innovation and growth. As regards transport innovation potential the comparative strengths of regions are not well known yet, also because innovation performances and capacities are difficult concepts to measure.

In this paper we explore the transport innovation potential of regions by discussing a method to measure and explain transport innovation performance of regions and applying this method to 251 European regions. The organization of the paper is as follows. The next section briefly reviews previous studies on innovation in the European transport sector and highlights some characteristics of the innovation activities in the transport sector in Europe. Then the framework to measure and explain the transport innovation performance of regions is presented and the results of the analysis are discussed. In the final section the key findings are summarized and the conclusions are drawn.

\section{Innovation in the Transport Sector in Europe}

There is a wide range of general studies which map regional innovation capacities and performances. Some studies map and investigate various regional dimensions of the innovative process (Pinto, 2009; Gössling and Rutten, 2007; De Bruijn, 2004) while others map regional innovation patterns and categorize regions according to their modes of performing different phases in the innovation process (Capello and Lenzi, 2013; Camagni and Capello, 2013). These studies investigate regional dimensions of innovation processes and innovation outcomes (e.g. innovation as an important driver for economic growth) in a general way and show that the various dimensions of innovations such as knowledge and funding have heterogeneous spatial impacts (Capello and Lenzi, 2014). It is possible that this is due to regional differences in economic specialization.

Another group of studies include this specialization in explaining regional differences in innovation. They identify regional clusters of innovation (Moreno et al., 
2005; Rodríguez-Pose and Comptour, 2012; De Dominicis et al., 2013) which are often linked to a spatial concentration of a particular sector (often only manufacturing sector). In some studies the manufacturing part of the transport sector can be distinguished. It appears that the spatial concentration of the transport manufacturing sector is more important in explaining its level of innovation activity than for the entire manufacturing industry (Moreno et al., 2005).

Studies that focus on innovation of the transport sector either lack a spatial dimension (Wiesenthal et al., 2015; Wiesenthal et al., 2011) or are focused on a particular region in which the regional innovation system or the innovation milieu of a particular subsector of the transport sector is analyzed (see for an overview Louw and Konings (2014)). According to Louw and Konings (2014) there are several regions in Europe that specialize in subsectors of the transport sector. There are several strong regional clusters in the automotive sector (particular in Germany), but only a few strong clusters in aviation such as the region around Toulouse in France. The transport service sector is more evenly distributed over Europe than the manufacturing automotive and aviation subsectors, nevertheless it has more strong clusters than the aviation subsector.

The general innovation studies (Wiesenthal et al., 2015; Wiesenthal et al., 2011) show large differences in innovation among the transport subsectors. Innovative products (either new to the market of new to the firm) contribute to almost $40 \%$ of the total turnover of the transport manufacturing sector in Europe, whereas for the transportation and storage service sector this is about $20 \%$. It is argued that this is due to the fact that transport service companies focus largely on reducing their costs and have lower incentives to invest in research and development. On the other hand it is argued that an important part of the subsector's innovation stems from the purchase of innovations from other industrial subsectors through the acquisition of advanced machinery, software and other equipment, instead of the financing of research activities (Wiesenthal et al., 2015).

In terms of research and development investments the automotive industry dominates the transport sector in Europe. In 2011 the automotive industry accounted for $81,5 \%$ of all R\&D investments in the transport sector. The civil aviation industry recorded about $13 \%$, while the remaining $6 \%$ is shared by the waterborne, rail, infrastructure and transport service providers (Wiesenthal et al., 2015).

From these studies it is clear that the transport sector as a whole is heterogeneous in terms of modes, technologies, customers, infrastructure and services, which are likely to lead to very different research activities across them (Wiesenthal et al., 2015). In general a distinction can be made between the manufacturing and the service sectors. Infrastructure is also a different subsector, but because this subsector has a very low level of $\mathrm{R} \& \mathrm{D}$ investment and is highly integrated in the construction sector it is hardly practical nor feasible to include this sector in the analysis. This heterogeneous nature of the transport sector is also expressed by the large number of studies on regional innovation systems of innovation milieus in regions with strong transport clusters. Most of these studies concentrate on transport subsectors in manufacturing (particular in automotive and aviation) but hardly in the service subsector. This is remarkable, 
because the service sector is in terms of employment and turnover larger than the manufacturing sector. The explanation may be that service innovations are not tangible and less noticeable, and therefore have received less attention.

\section{Framework for Measuring and Explaining Transport Innovation Performance}

\subsection{Conceptual Model}

Innovation performance in general is being measured on a regular base across the European Union. The most extensive measurement tool is the Union Innovation Scoreboard (UIS), which provides an annual benchmark of the innovation performance at the country level of the EU member states and other European countries. Innovation performance is measured using a composite indicator - the Summary Innovation Index
- which summarizes the performance of a range of different indicators. IUS distinguishes between 3 main types of indicators - Enablers, Firm activities and Outputs - and 8 innovation dimensions, capturing in total 25 indicators (see Fig. 1).

The other measurement tool, the Regional Innovation Scoreboard (RIS), accompanies the UIS. The RIS provides a comparative assessment of innovation performance across 190 regions of the European Union, Norway and Switzerland, but it is less frequent and detailed due to lack of innovation data at the regional level. The RIS 2014 uses data for 11 of the 25 indicators in the UIS (see Fig. 1). Similar as in the IUS where countries are classified into 4 different innovation performance groups, Europe's regions have also been classified into Regional Innovation leaders (34 regions), Regional Innovation followers (57 regions), Regional Moderate innovators (68 regions) and Regional Modest innovators (31 regions) (Hollanders et al., 2014).

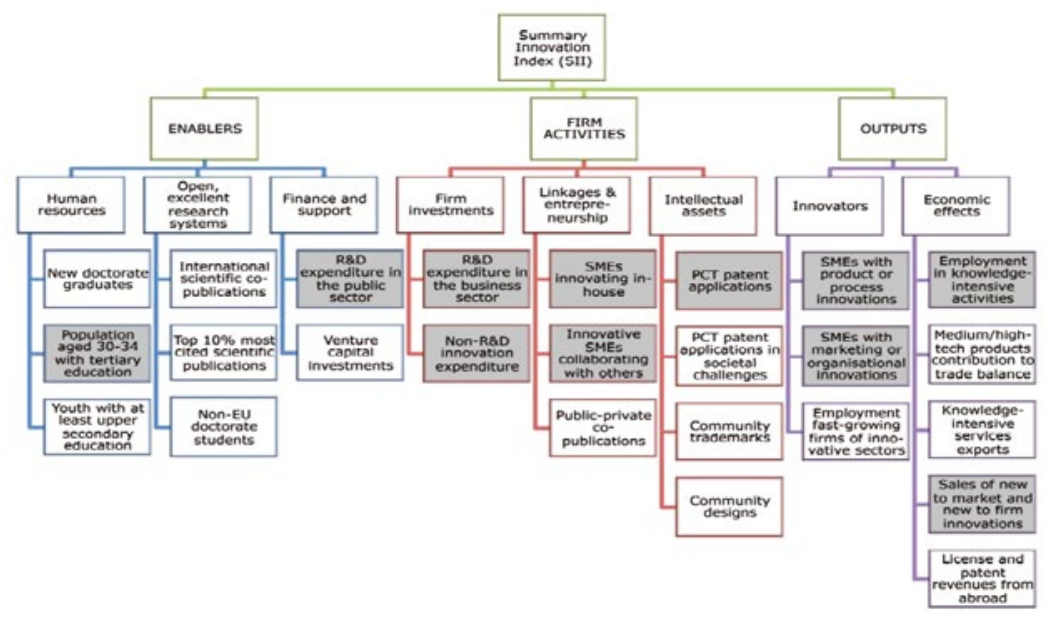

Indicators included in the Regional Innovation Scoreboard only.

Fig. 1.

Measurement Framework of Union Innovation Scoreboard and Regional Innovation Scoreboard Source: Hollanders et al. (2014) 
In order to measure the transport innovation performance of regions it would have been logic to adopt the approach of the UIS and the RIS. The limited availability of data at regional level, however, becomes even more problematic when regional data needs to be collected at sectoral level, i.e. the transport sector. For several of the indicators in the
RIS data are not available at the level of the transport sector. On the other hand data regarding relevant indicators to measure transport innovation performance are only available at country level. In view of these limitations the RIS measurement framework has been adopted to the framework as presented in Fig. 2.

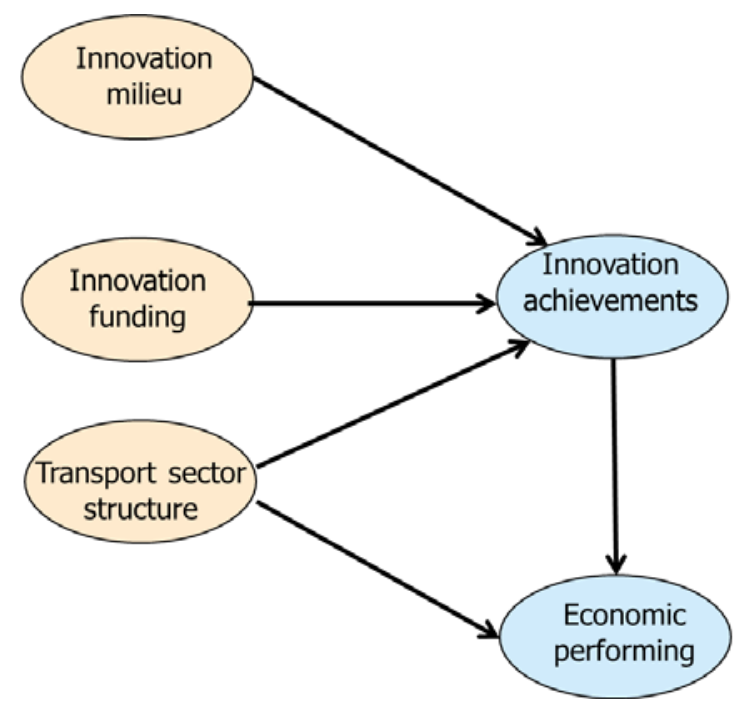

Fig. 2.

Measurement Framework of Regional Transport Innovation Performance

Two dimensions have been distinguished to measure regional transport innovation performance (see also Hollanders et al. (2012)):

- Innovation achievements: captures the output of innovation activities in the transport sector in the region;

- Economic performing: captures the economic effects of innovation activities in the transport sector in the region.

Consistent with what is often quoted in literature (see for an overview: Konings and Louw (2014)) as relevant to encourage innovation activities and to succeed in the implementation of innovations we have defined the following factors to explain innovation achievements: innovation milieu, innovation funding and transport sector structure. In addition, it is assumed that the economic performing of the transport sector can be explained by innovation achievements. Innovation may induce better economic performing, but the level of economic performing of the transport sector will obviously also be determined by other factors. These other effects on the regional economic performing of the 
transport sector are supposed to be caused by the characteristics of the transport sector in general (see Fig. 2).

\subsection{Indicators: Data}

The next step was to define indicators to enable the measurement of 'Innovation achievements', 'Economic performing', 'Innovation funding', 'Innovation milieu' and 'Transport sector structure'. The availability of data played a key role in this process. We wanted to conduct our regional analysis at the NUTS (Nomenclature of Units for Territorial Statistics) level 2, since this level captures regions (administrative units) that are most relevant for the application of regional policies (15). On NUTS 2 level, the EU-27 consists of 264 regions. The data at NUTS 2 level could largely be obtained from Eurostat statistics. Other sources were the Joint Research Centre of the European Commission and the Cluster observatory (Cluster Observatory, 2014). However, not all data were available at the NUTS 2 level. For instance, data from the Community Innovation Survey (CIS) from Eurostat were only available at country level. Where needed the data have been regionalized according to the regionalization technique proposed in the RIS 2014 (Hollanders et al., 2014). Furthermore, the number of missing values in the data have been reduced by using different imputation techniques (Konings and Louw, 2014b). Regions with a substantial number of missing values, however, were dropped. In the end 251 regions were kept for the analysis. The data for the transport sector covered both the manufacturing sector (i.e. vehicles and other transport equipment) and the transport service sector. The following indicators were used (Konings and Louw, 2014a; Konings and Louw, 2014b):
Innovation achievements:

- Share of innovative enterprises in the transport sector.

- Share of highly innovative enterprises in the transport sector.

- Average number of patents per year per 100.000 employees.

- Share of enterprises that have introduced new or significant improved products that were new to the market.

- Share of enterprises that have introduced new or significant improved products that were only new to the firm.

- Share of turnover from innovations.

Economic performing:

- Growth of value added in the transport sector.

- Growth of employment in the transport sector.

- Growth of labor productivity in the transport sector.

Transport sector structure:

- Average firm size.

- Share of manufacturing (or services) in total employment of the transport sector.

- Level of transport specialization.

Innovation funding:

- Share of product and/or process innovative enterprises that received any public funding.

- Share of public R\&D as \% of GDP.

- Share of business R\&D as \% of GDP.

- Share of government R\&D spending on transport.

Innovation milieu:

- Specialization in transport research as \% of total EC funding (in the $7^{\text {th }}$ Framework Program). 
- Cluster Quality.

- Population density.

- Share of product and/or process innovative enterprises engaged in any type of co-operation.

- Share of high educated persons in the total transport employment.

- Share of persons employed in science and technology in total of all manufacturing activities and in transport services.

- Share of employment in technology and knowledge-intensive sectors in transport services.

- Educational level of the total labor force.

\subsection{Structural Equation Modelling (SEM)}

SEM is a statistical technique to investigate complex causal relations through combining the technique of regression analysis, path analysis and factor analysis. For the purpose of our analysis SEM is an appropriate tool, because it enables a comprehensive measurement of the innovation performance of regions in the transport sector and it enables to get insights in the relative importance of the explanatory factors for the transport innovation performance.

The influence of the explanatory factors is revealed in the so called structural model of SEM, while scores on the factors, i.e. 'Innovation achievements' and etc., are obtained through the so called measurement model of SEM. Usually both models are run simultaneously in SEM, and hence all estimations are obtained in one time. Special software exists (e.g. AMOS in SPSS) to run SEM-models. This approach, however, could not be applied here. The limited number of observations (251 regions) related to the relative large number of parameters to estimate (caused by the number of factors and their relations and indicators) caused difficulties in fitting the model. A possibility to overcome this estimation problem was to construct factors by their indicators before the AMOS analysis was undertaken. Hence a two-step approach was taken in which the scores of factors are input for the SEM-model (i.e. the structural part of the model).

Different methods exist to compute the factor scores, all having some advantages and disadvantages. Based on decision rules and recommendations provided in literature about multivariate data analysis (see e.g. Hair et al. (1998)) we have chosen for the method of summated scales (= somscores). This means that each indicator gets an identical weight in the construction of the factor. In order to apply the summated scales all indicators have been standardized by means of transforming their original values into Z-scores.

\section{Results of the SEM Analysis}

The type of activities in the transport sector of a region can be very diverse. The activities are in particular different between transport manufacturing and service companies, and hence differences are also very likely in their innovation behavior and performance (as already outlined in section 2). A region may show a good innovation performance in transport manufacturing, while the transport service companies may have a weak innovation performance. It is important to note that the innovation performance of the total transport sector can be a result of very different performances in the two subsectors. Therefore a SEM analysis is performed for the total transport sector, but also for the transport manufacturing and transport service sector individually. 


\subsection{Model Estimations for the Total Sector}

The estimations for the total sector are shown in Fig. 3, i.e. the standardized path coefficients, which express the strength of the causal relations (the single arrows) and the R squares for 'Innovation achievements' and 'Economic performing' (at the right top of the boxes), which express the (local) explanatory strength of the model. The double arrows express the correlations between the explanatory factors and have been included to obtain a pure effect estimation of each explanatory factor only.

'Funding' is the most important determinant (0.69) for 'Innovation achievements', followed by 'Sector structure' (0.30). The role of 'Innovation milieu' should be interpreted as negligible as the path coefficient is close to zero. In view of theoretical notions this is a remarkable result. Specific attention was given to the composition of indicators in this factor. Several variants in the composition of indicators - in which fewer indicators were included - were tested in different model runs. The results, however, were robust. That is to say, they did not lead to relevant changes in the path coefficient that describes the strength of the influence of 'Innovation milieu' on 'Innovation achievements'. Therefore we kept the original composition of indicators for the factor 'Innovation milieu'.

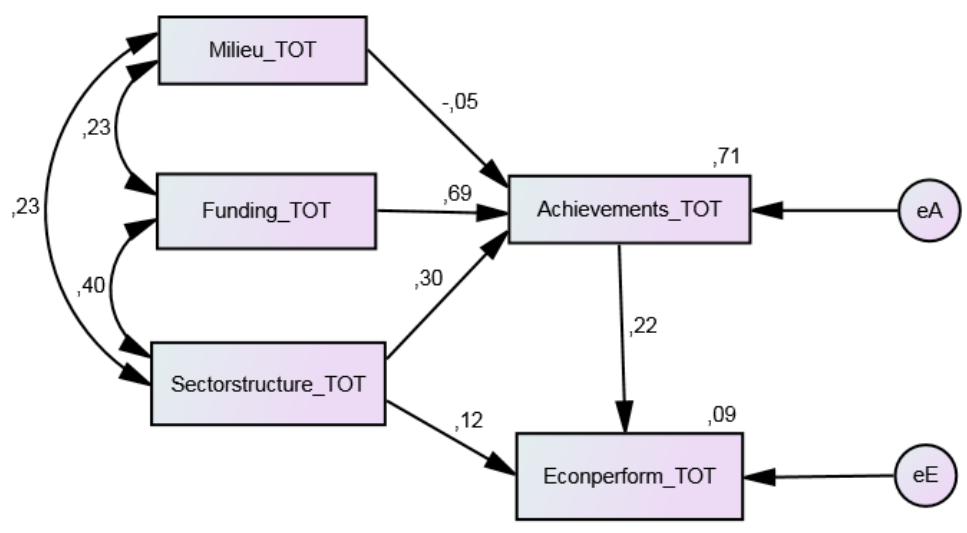

Fig. 3.

Parameter Estimations for the Total Transport Sector

Fig. 3 also shows that 'Innovation achievements' are a significant determinant for the 'Economic performing' of the transport sector of a region. In addition, there is a direct effect of 'Sector structure' on the 'Economic performing' (0.12) as well as an indirect effect that is induced via 'Innovation achievements'. In the right corner, on top of the endogenous factors the R-square is plotted. It seems that the 'Innovation achievements' are quite well explained by the factors 'Funding', 
'Transport sector structure' and 'Innovation milieu'. On the other hand the 'Economic performing' of the transport sector can, to a very low extent, be explained by this model. Apparently, there are others factors relevant for the 'Economic performing' which are not included in this model.

In Fig. 4 the relative scores of the regions on 'Innovation achievements' are mapped. In this map two categories represent the scores of regions above the European average ('above average' and 'far above average') and two categories reflect the scores below the European average ('below average' and 'far below average'). The high performing regions are predominantly in Germany, and, remarkably, regions in Portugal and Sweden also score well. On the other hand regions in France, Spain, Norway, Hungary and in particular in Finland, Poland, Romania and Bulgaria are at the lower end of the scores.

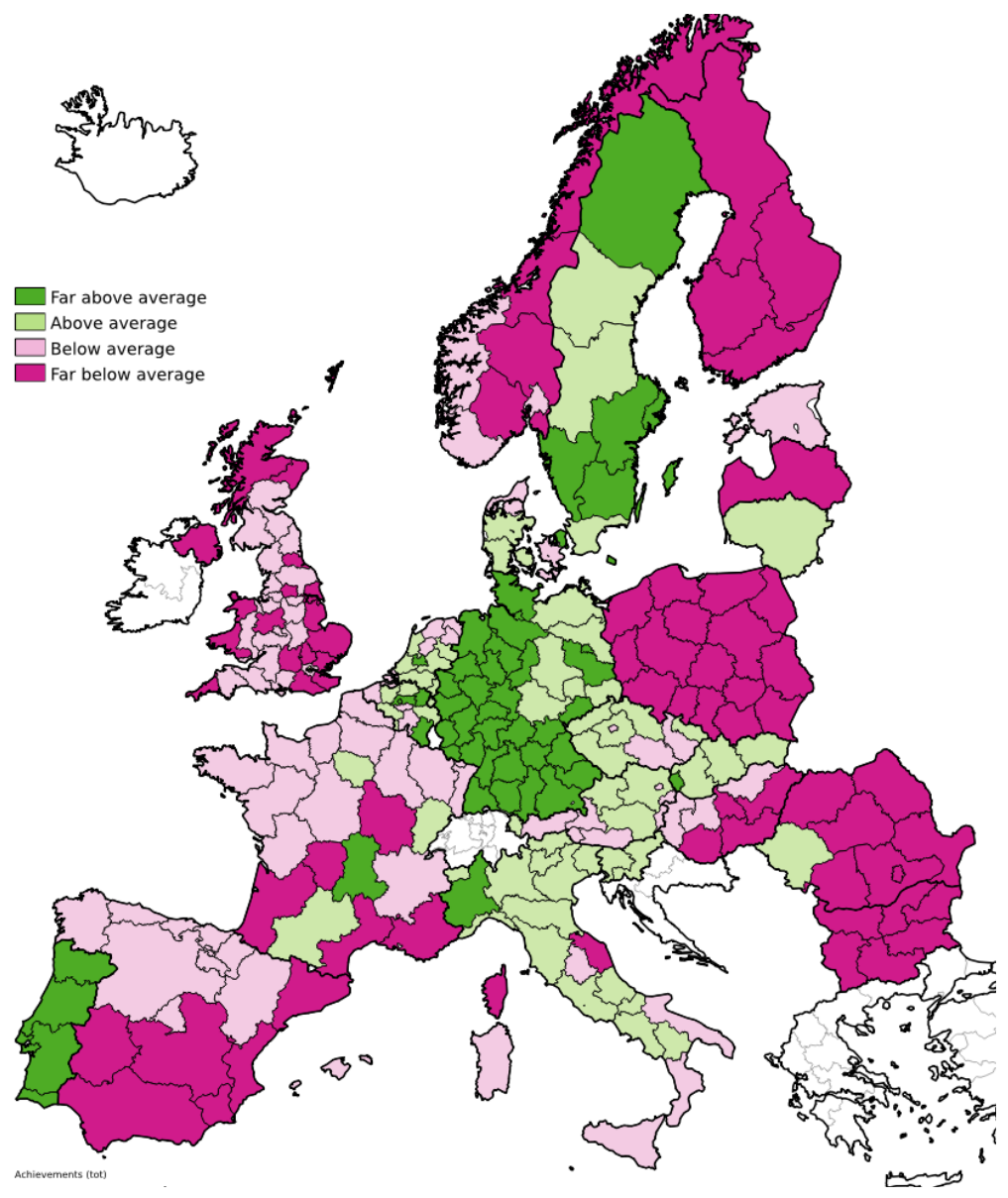

Fig. 4.

Scores of Regions on 'Innovation Achievements' in the Total Transport Sector 


\subsection{Model Estimations for the Transport Manufacturing Sector}

Fig. 5 depicts the result of the analysis for the transport manufacturing sector only. Both 'Funding' and 'Transport sector structure' seem to be important for 'Innovation achievements' in this subsector. The role of 'Transport sector structure' may point at the relevance of 'mass' to achieve strong innovation performances in the manufacturing sector. Namely, the presence of large companies and a high share of transport manufacturing companies go along with high scores on 'Innovation achievements' of regions. The importance of 'Innovation milieu' for 'Innovation achievements' appears also for the manufacturing sector marginal. The variance in 'Innovation achievements' which is explained by the model (0.61) is nevertheless substantial.

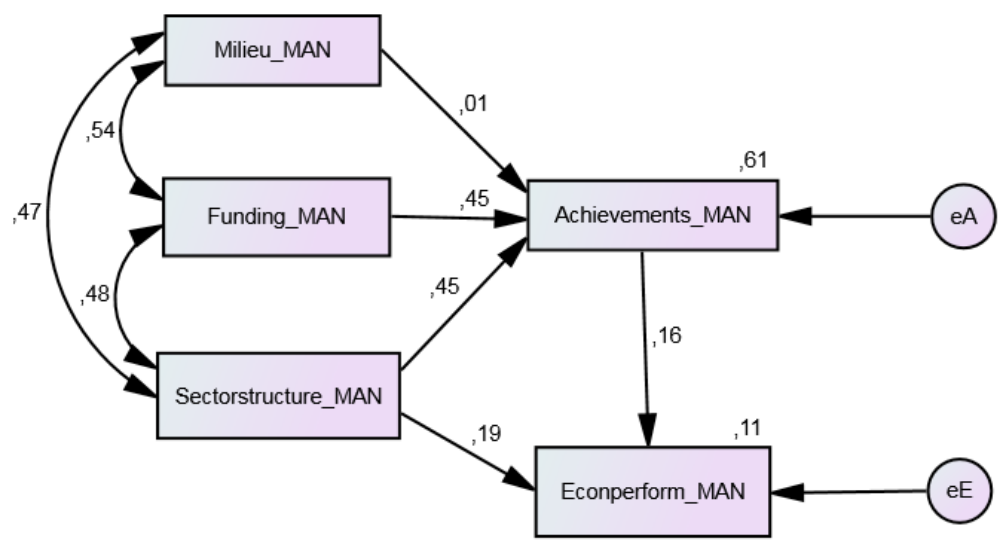

Fig. 5.

Parameter Estimations for the Transport Manufacturing Sector 


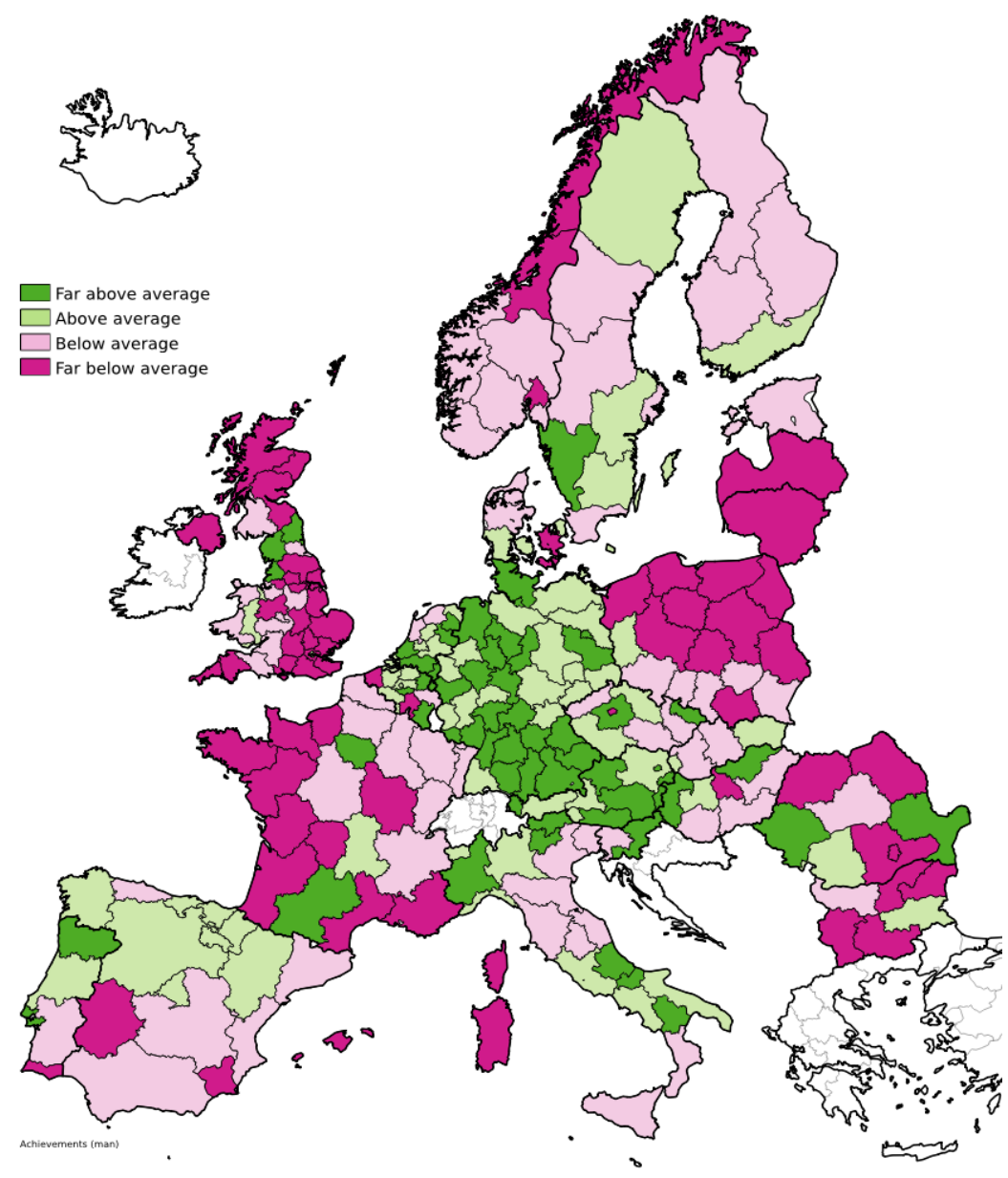

Fig. 6.

Scores of Regions on 'Innovation Achievements' in the Transport Manufacturing Sector

The relative scores of regions on 'Innovation Achievements' are mapped in Fig. 6. Many regions that have a high innovation performance are found in Germany, but also a lot of other countries have some regions that perform well, such as France, Italy, Portugal, the Netherlands, Belgium, Austria, Czech Republic, Hungary, United Kingdom Romania and Sweden. The pattern of high performing regions is partly framed by the location pattern of the car manufacturing industry. Several regions that have a weak innovation performance in transport manufacturing are located in France, United Kingdom and Poland. Compared to the map that covers 'Innovation achievements' in the total transport sector, the strong performing regions in the manufacturing sector on one hand and the weak performing regions on the other hand are less geographically clustered. 


\subsection{Model Estimations for the Transport Service Sector}

The results for the SEM-analysis for the transport service sector only (see Fig. 7) are rather different from the manufacturing sector, but resemble the results for the total sector. This can be explained by the fact that there are much more transport service activities (in terms of employment and companies) than transport manufacturing activities. Hence the strengths of relationships found in the service sector put their mark on strengths of relationships observed in the total transport sector.

'Funding' appears to be by far the most important determinant for 'Innovation achievements' in the service sector. There is a modest role of 'Transport sector structure' in influencing the 'Innovation achievements', but the quality of 'Innovation milieu' here also appears not important. The power of the model to explain 'Innovation achievements' is, however, relatively good (comparable to the models for the total and the manufacturing transport sector). Note that the model of the service sector is not able to explain the 'Economic performing' of the transport services. There appears to be a weak and even negative relation between 'Innovation achievements' and 'Economic performing'. The influence of 'Transport sector structure' on the 'Economic performing' is also negligible. We cannot explain why these results are different from the models for manufacturing and the total transport sector.

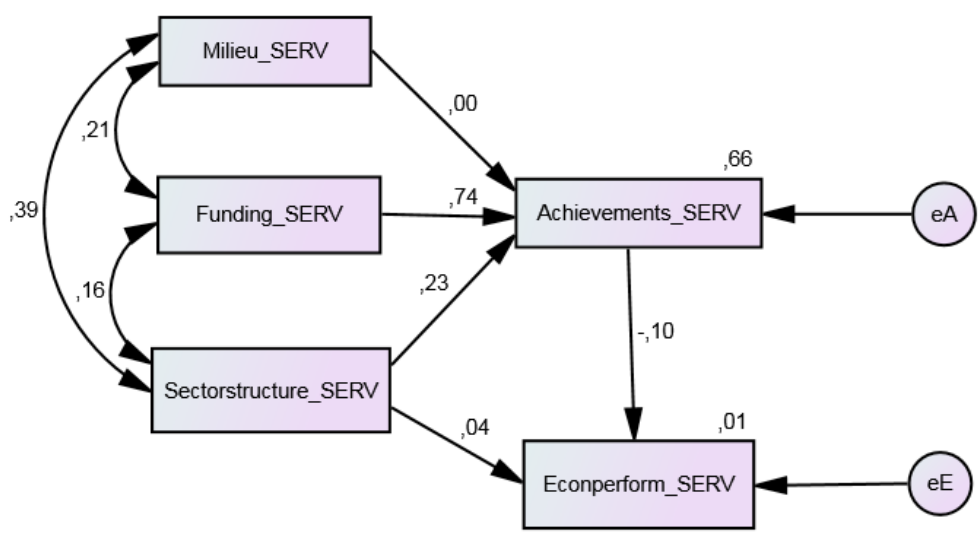

Fig. 7.

Parameter Estimations for the Transport Service Sector

Fig. 8 illustrates the regional scores on 'Innovation achievements' in the service sector. Regions that are in a similar range of performance are largely clustered geographically. High performing regions are found in Germany, Sweden and Portugal. Italy has for example many moderate performing regions and United Kingdom 
very modest performing regions. The lowest Spain, Norway, Poland, Slovakia, Hungary, performing regions are strongly clustered in Romania and Bulgaria.

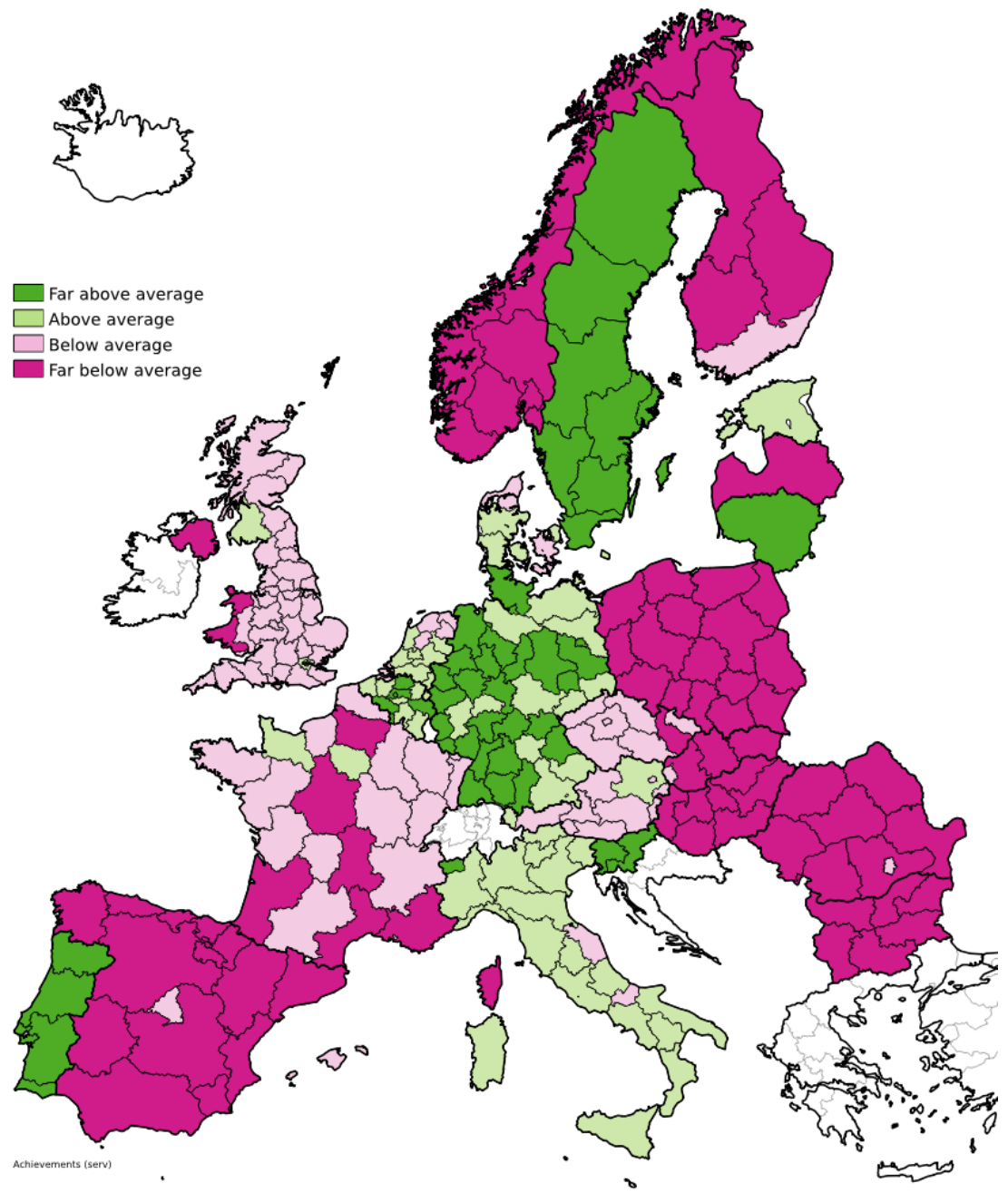

Fig. 8.

Scores of Regions on 'Innovation Achievements' in the Transport Service Sector

\section{Conclusions}

In this paper we have measured the innovation performance of the transport sector at regional level. We used an approach that enabled a comprehensive measurement that took into account that there is not one unambiguous indicator to measure performance, but rather a set of indicators since performance actually has several dimensions. 
A major observation from our analysis is that the relative innovation performance of regions is strongly determined by the definition of the transport sector. First the innovation performance of regions was measured for the total transport sector, i.e. the transport manufacturing and service activities together. This definition is obviously relevant to map the innovation performance of regions in general. However, because manufacturing and service activities are so different, and most likely also the innovation behavior of these subsectors, but also because of large differences between regions in the relative size of the transport manufacturing and service sector it made sense to look also at the innovation performance of these subsectors separately.

The results for the total transport sector showed that the high performing regions were predominantly found in Germany and Sweden, while the low performing regions were located in Finland, Poland, Romania, Bulgaria, Hungary, Spain and UK. Since the transport service sector is much greater (in terms of employment and number of companies) than the manufacturing sector, the scores of regions in the service sector resemble the scores for the total transport sector. The map of innovation performances of regions in the manufacturing sector gave a more diversified pattern, i.e. more regional variation within the different countries.

In order to explore explanations for the transport innovation performance of regions and their relative performances a Structural Equation Model (SEM) was used. From general innovation theory relevant factors to explain innovation performance were related to the innovation achievements, i.e. funding, innovation milieu and transport sector structure. Several indicators were used to enable a comprehensive measurement of these factors.

The results of this SEM-analysis indicate a relative great importance of funding possibilities for the innovation achievements. This observation was valid for both the analysis for the total transport sector and for the analyses of the manufacturing and service sectors. However, the role of funding appears to be even more important in the service than manufacturing sector. In general the results suggest that the availability and possibilities for innovation funding are determined at national level rather than regional level, since the scores of regions on funding show hardly variation between regions within countries. The importance of the transport sector structure for innovation achievements is in the manufacturing sector greater than in the service sector. Furthermore, the importance of innovation milieu for the innovation achievements appears to be negligible for both the manufacturing and service sector. This finding does not correspond well to general theoretical expectations, and therefore gave rise to critical reviews and revisions in the construction of the innovation milieu factor (i.e. the composition of its indicators). However, this did not lead to significant changes in the outcome. All in all, this finding may indicate at some unknown peculiarities of the transport sector that make the relevance of conditions to innovate in this sector different from other sectors.

In our research we were faced with the fact that we could only use secondary data, and as the experiences with the RIS have shown, there is limited availability of data. In principle we needed comparable data as used in the RIS, but even more detailed, because it 
was needed at sectoral level (i.e. the transport sector). Therefore it took great efforts to obtain regional data for all indicators that were initially proposed to be included in the SEM-model. For several indicators the data appeared too incomplete to keep them in the analysis, while for other indicators, a lot of data imputation (e.g. regionalization of data) was needed. It is uncertain to what extent this leads to biasedness and has affected our model results. Considering the great emphasis the European Commission places to innovation policy and research it is recommended to extend and improve the data collection to support research in this field.

\section{Acknowledgements}

The results presented in this paper have received funding from the European Union's Seventh Framework Programme (FP7/20072013) under grant agreement $n^{\circ} 605428^{\prime}$.

\section{References}

Camagni, R.; Capello, R. 2013. Regional Innovation Patterns and the EU Regional Policy Reform: Toward Smart Innovation Policies, Growth and Change, 44(2): 355-389.

Capello, R.; Lenzi, C. 2013. Territorial patterns of innovation: a taxonomy of innovative regions in Europe, The Annals of Regional Science, 51(1): 119-154.

Capello, R.; Lenzi, C. 2014. Spatial heterogeneity in knowledge, innovation, and economic growth nexus: conceptual reflections and empirical evidence, Journal of Regional Science, 52(2): 186-2214.

Cluster Observatory 2014. Clusters at your fingertips. Available from Internet: <http://www. clusterobservatory.eu $>$.
De Bruijn, P.J.M. 2004. Mapping innovation: regional dimensions of innovation and networking in the Netherlands, Tijdschrift voor Econimische en Sociale Geografie, 95(4): 433-440.

De Dominicis, L.; Florax, R.J.G.M.; de Groot, H.L.F. 2013. Regional clusters of innovative activity in Europe: are social capital and geographical proximity key determinants?, Applied Economics, 45(17): 2325-2335.

European Union 2013. Employment in the EU transport sector, Luxembourg.

European Union 2102. Innovating for a competitive and resource-efficient transport system, Luxembourg.

Gössling, T.; Rutten, R. 2007. Innovation in Regions, European Planning Studies, 15(2): 253-270.

Hair, J.F.; Anderson, R.E.; Tatham, R.L.; Black, W.C. 1998. Multivariate data analysis, Fifth edition. New Jersey: Prentice Hall.

Hollanders, H.; Derbyshire, J.; Lewney, R.; Tijssen, R.; Tarantola, S.; Rivera Leon, L. 2012. Regional Innovation Scoreboard 2012, Methodology report, Brussels.

Hollanders, H.; Es-Sadki, N.; Buligescu, B.; Rivera Leon, L.; Griniece, E.; Roman, L. 2014. Regional Innovation Scoreboard 2014, Brussels: European Union, DirectorateGeneral for Enterprise and Industry.

Konings, R.; Louw, E. 2014. Transport innovation indicators, [METRIC project deliverable 3.1], Delft: Delft University of Technology.

Konings, R.; Louw, E. 2014. Transport research and innovation performance of regions, [METRIC project deliverable 3.2], Delft: Delft University of Technology.

Louw, E.; Konings, R. 2014. Structure and role of the innovative milieu, [METRIC project deliverable 2.2], Delft: Delft University of Technology. 
Moreno, R.; Paci, R.; Usai, S. 2005. Geographical and sectoral clusters of innovation in Europe, The Annals of Regional Science, 39(4): 715-739.

Pinto, H. 2009. Diversity of Innovation in the European Union: Mapping Latent Dimensions and Regional Profiles, European Planning Studies, 17(2): 303-326.

Rodríguez-Pose, A.; Comptour, F. 2012. Do Clusters Generate Greater Innovation and Growth? An Analysis of European Regions, The Professional Geographer, 64(2): 211-231.
Wiesenthal, T.; Condeço-Melhorado, A.; Leduc, G. 2015. Innovation in the European Transport Sector: A Review, Transport Policy, 42: 86-93.

Wiesenthal, T.; Leduc, G.; Cazzola, P.; Schade, W.; Köhler, J. 2011. Mapping innovation in the European transport sector. An assessment of R\&D efforts and priorities, institutional capacities, drivers and barriers to innovation. Publication JRC 63913, European Commission, Joint Research Centre. 